BRADY AND BOWMAN : DINITROTOLYLHYDRAZINES.

\title{
C.-Dinitrotolylhydrazines.
}

By Oscar lisle Brady and John Herbert Bowman.

GIUA (Gazetta, 1919, 49, ii, 166) has described the action of hydrazine hydrate on $3: 4: 6$ - and $2: 3: 4$-trinitrotoluenes. In the former case, he obtained $4: 6$-dinitro- $m$-tolylhydrazine, but in the latter he did not isolate the hydrazine, but a compound richer in nitrogen, melting and decomposing at $150^{\circ}$, which he suggests may be a nitronitrosotolylhydrazine or a nitrohydroxymethylbenzotriazole,

$$
\mathrm{NO}_{2} \cdot \mathrm{C}_{6} \mathrm{H}_{2} \mathrm{Me}<\underset{\mathrm{N}(\mathrm{OH})}{-\mathrm{N}}>\mathrm{N} \text {. }
$$

This reaction had been observed by one of us before the publication of Giua's work, but had not been fully investigated. As the results obtained at that time were at variance with those of Giua with respect to the action of hydrazine hydrate on $2: 3: 4$-trinitrotoluene, the reaction has been studied further and extended to the other trinitrotoluenes containing a mobile nitro-group.

It has been found that by the action of hydrazine hydrate on $2: 3: 4-, 2: 3: 5$-, and $3: 4: 5$-trinitrotoluenes the corresponding dinitrotolylhydrazines are formed, as in the case of $3: 4: 6$-trinitrotoluene. The compounds have been oriented by oxidation of the hydrazino-group to hydrogen by means of cupric acetate and identification of the dinitrotoluene produced. In every case it was found that the nitro-group replaced by the hydrazine residue was the same as that displaced by ammonia and other amines.

The dinitrotolylhydrazines are readily crystallisable substances which undergo the usual reactions of arylhydrazines. Oxidation with cupric chloride and with iodine replaces the hydrazino-group by chlorine and iodine respectively. They form hydrazones with aldehydes and ketones, which, on account of their high, sharp melting points, their sparing solubility, and the ease with which they may be prepared and crystallised, are very convenient for the identification of these substances.

With $2: 3: 6$-trinitrotoluene, the reaction did not proceed in 
the normal manner (compare Drew, T., 1920, 117, 1616) and an oily product was obtained, which has not been further investigated owing to lack of material. This result, however, is in accord with the work of other investigators who experienced a similar difficulty in replacing the nitro-group with ammonia (Körner and Contardi, Atti R. Accad. Lincei, 1916, [v], 25, ii, 339).

Some explanation is necessary of the discrepancy between our results and those of Giua in the case of $2: 3: 4$-trinitrotoluene. In the preparation of $4: 6$-dinitro- $m$-tolylhydrazine from $3: 4: 6$ trinitrotoluene, Giua used 2 grams of 50 per cent. hydrazine hydrate for $2 \cdot 27$ grams of the trinitrotoluene, but in the case of the $2: 3: 4$ compound, only 1.5 grams of the hydrate, that is, one and a half molecular proportions. As the reaction that takes place is

$$
\begin{aligned}
\mathrm{C}_{6} \mathrm{H}_{2} \mathrm{Me}\left(\mathrm{NO}_{2}\right)_{3}+2 \mathrm{NH}_{2} \cdot \mathrm{NH}_{2}, \mathrm{H}_{2} \mathrm{O} & \longrightarrow \mathrm{C}_{6} \mathrm{H}_{2} \mathrm{Me}\left(\mathrm{NO}_{2}\right)_{2} \cdot \mathrm{NH} \cdot \mathrm{NH}_{2}+\mathrm{HN}_{3}+4 \mathrm{H}_{2} \mathrm{O},
\end{aligned}
$$

this amount is insufficient. Using Giua's quantities, a substance melting at $154^{\circ}$ was obtained, and it was found that this was a mixture of the dinitrotolylhydrazine and the hydrazine salt of nitrohydroxymethylbenzotriazole. Owing to the sparing solubility of this hydrazine salt in cold alcohol, it cannot easily be removed by crystallisation of the mixture from this solvent, the method of purification employed by Giua, but it can readily be got rid of by washing with cold water.

Giua's substance cannot be the benzotriazole compound, as this has now been prepared by the action of excess of hydrazine hydrate or of alcoholic sodium hydroxide on the dinitrotolylhydrazine and found to be quite different from the compound described by him. The orientation of the benzotriazole derivative has not yet been

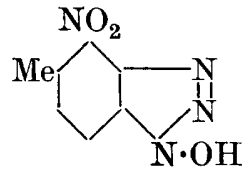

(I.)

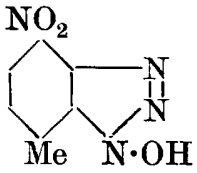

(II.)

established; the compound may be either 4-nitro-1-hydroxy-5methyl-1:2:3-benzotriazole (I) or 4-nitro-1-hydroxy-7-methyl$1: 2: 3$-benzotriazole (II).

A fuller description of compounds of this class will be made the subject of a further communication.

Another possibility was that the azoimide formed in the reaction had reacted with the excess of trinitrotoluene to give the triazocompound, $\mathrm{C}_{6} \mathrm{H}_{2} \mathrm{Me}\left(\mathrm{NO}_{2}\right)_{2} \cdot \mathrm{N}_{3}$. This compound has also been prepared and found to melt at $89^{\circ}$. 
A dinitrotolylhydrazine is mentioned by Borsche and Fiedler (Ber., 1913, 46, 2129), but they give no description or analysis. Their compound was obtained by the action of hydrazine hydrate on a compound supposed by these authors to be 3-chloro-2:4dinitrotoluene melting at $73^{\circ}$. This compound was obtained as a by-product in the nitration of $m$-chlorotoluene and its structure assigned by analogy, on account of its similarity to 1-chloro-2:6dinitrobenzene. We have, however, prepared 3-chloro-2 :4-dinitrotoluene by the action of cupric chloride on $2: 4$-dinitro- $m$-tolylhydrazine and found it to melt at $93^{\circ}$. It seems probable that Borsche and Fiedler's compound was 3-chloro-2 : 6-dinitrotoluene, which Körner and Contardi prepared (loc. cit.) and found to melt at $75^{\circ}$. The formation of this compound in small quantities in the nitration of $m$-chlorotoluene rather than the $2: 4$-dinitroderivative might be expected from the course of the nitration of aceto- $m$-toluidide. Here the main product of nitration is the $4: 6$-dinitro-derivative, a small quantity of the $2: 6$-, but no $2: 4$ dinitro-compound being formed (Cook and Brady, T., 1920, 117, 750 ). Similarly, the lack of reactivity of the chlorine atom noticed by Borsche and Fiedler is in accordance with the observations of Körner and Contardi and others on the abnormal behaviour of 2:3:6-trinitrotoluene. It appears, therefore, that Borsche and Fiedler's dinitrotolylhydrazine and the benzotriazole they prepared from it (decomposing at $110-170^{\circ}$ ), which Giua in a later paper (Gazzetta, 1920, 50, ii, 327) suggests might be identical with his compound melting at $150^{\circ}$, have been incorrectly oriented and are $2: 3: 6$-trisubstituted derivatives.

EX P E R I M E N T A L.

\section{$2:$ 4-Dinitro-m-tolylhydrazine.}

Eleven grams of $2: 3: 4$-trinitrotoluene were dissolved in 150 c.c. of boiling alcohol and 10 c.c. of hydrazine hydrate (50 per cent.) diluted with 20 c.c. of alcohol added. The mixture, which acquired a deep red tint, was cooled at once in a stream of water, when the hydrazine separated in red crystals. If the mixture is boiled, the excess of hydrazine will react with the dinitrotolylhydrazine to give the benzotriazole, with consequent loss of yield; under the above conditions, however, an 80 to 90 per cent. yield of an almost pure product is obtained. 2:4-Dinitro-m-tolylhydrazine crystallises from boiling alcohol or benzene in long, red, prismatic needles melting at $170^{\circ}$ (Found: $\mathrm{N}=26 \cdot 8 . \quad \mathrm{C}_{7} \mathrm{H}_{8} \mathrm{O}_{4} \mathrm{~N}_{4}$ requires $\mathrm{N}=26 \cdot 4$ per cent.). The hydrazine is soluble in warm 10 per cent. hydro- 
chloric acid, but the hydrochloride is readily hydrolysed and dilution of the acid solution causes precipitation of the base.

Acetyl-2:4-dinitro-m-tolylhydrazine.-The above hydrazine was dissolved in four to five times its weight of warm acetic anhydride. On cooling, the acetyl derivative separated. It crystallised from alcohol in long, brilliant yellow, rhombic needles melting and decomposing at $193^{\circ}$ (Found: $\mathrm{N}=22 \cdot 3 . \quad \mathrm{C}_{9} \mathrm{H}_{10} \mathrm{O}_{5} \mathrm{~N}_{4}$ requires $\mathrm{N}=22 \cdot 0$ per cent.).

Orientation of 2:4-Dinitro-m-tolylhydrazine.-The hydrazine was heated on the water-bath for thirty minutes in glacial acetic acid with excess of cupric acetate. The mixture was cooled, diluted with a large excess of water, and after leaving for some time filtered. The solid was extracted with hot alcohol to eliminate inorganic matter and the dinitrotoluene precipitated from the solution by dilution with water. On crystallisation, it melted at $70^{\circ}$ and did not depress the melting point of $2: 4$-dinitrotoluene (m. p. 70.5).

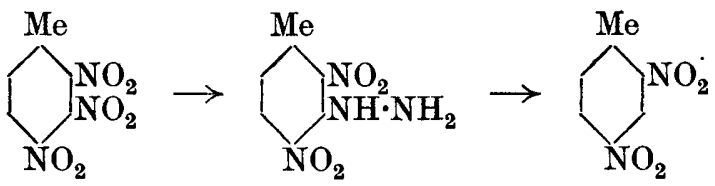

\section{3-Chloro-2 : 4-dinitrotoluene.}

Five grams of the hydrazine were dissolved in boiling alcohol and 20 grams of cupric chloride slowly added thereto, when copious evolution of nitrogen occurred. The mixture was cooled and filtered, but a certain amount of cuprous chloride remained in solution and was precipitated on dilution with the chloro-compound, from which it was difficult to remove. Consequently, the alcoholic solution was treated with concentrated hydrochloric acid and a little hydrogen peroxide on the water-bath for an hour to reoxidise the cuprous salt. The solution was then diluted and the precipitate recrystallised from alcohol, when 3-chloro-2:4-dinitrotoluene separated in long, silky, pale yellow needles melting at $92^{\circ}$ (Found: $\mathrm{Cl}=16 \cdot 2 . \quad \mathrm{C}_{7} \mathrm{H}_{5} \mathrm{O}_{4} \mathrm{~N}_{2} \mathrm{Cl}$ requires $\mathrm{Cl}=16 \cdot 4$ per cent.).

\section{3-Iodo-2 : 4-dinitrotoluene.}

A solution of 3 grams of the hydrazine in boiling alcohol was treated with excess of iodine. The mixture was boiled for thirty minutes, the excess of iodine removed with sulphurous acid, and the compound precipitated by the addition of water. 3-Iodo-2:4dinitrotoluene crystallises from alcohol in yellow leaflets melting at $117^{\circ}$ (Found : $\mathrm{N}=9 \cdot 4 . \quad \mathrm{C}_{7} \mathrm{H}_{5} \mathrm{O}_{4} \mathrm{~N}_{2} \mathrm{I}$ requires $\mathrm{N}=9 \cdot 1$ per cent.) 


\section{4-Niiro-1-hydroxy-5 (or 7)-methyl-1 : 2 : 3-benzotriazole.}

A hot alcoholic solution of 2 grams of $2: 4$-dinitro- $m$-tolylhydrazine was boiled for five minutes with 2 c.c. of 50 per cent. hydrazine hydrate. Orange-yellow crystals of the hydrazine salt began to separate at once, the quantity increasing when the mixture was cooled. The crystals of the salt were dissolved in water and the solution was acidified with dilute hydrochloric acid, when the benzotriazole derivative was precipitated. It crystallised from hot alcohol in very pale yellow, hexagonal prisms containing a molecule of water of crystallisation, which was lost at $100^{\circ}$, the compound then acquiring a lemon-yellow colour. By heating in a meltingpoint tube, the water was first driven off and the anhydrous compound then melted and decomposed at $205^{\circ}$ (Found: $\mathrm{N}=26 \cdot 6$; $\mathrm{H}_{2} \mathrm{O}=8 \cdot 7 . \quad \mathrm{C}_{7} \mathrm{H}_{6} \mathrm{O}_{3} \mathrm{~N}_{4}, \mathrm{H}_{2} \mathrm{O}$ requires $\mathrm{N}=26 \cdot 4 ; \mathrm{H}_{2} \mathrm{O}=8.5$ per cent.). This compound may also be obtained by treating a hot, alcoholic solution of the hydrazine with 10 per cent. alcoholic sodium hydroxide until a permanent red colour is obtained. On cooling, the sodium salt crystallises and may be decomposed with acids as before.

The benzotriazole derivative is slightly soluble in water, giving a brilliant yellow solution, but is less soluble in dilute hydrochloric acid; it is readily soluble in caustic alkalis and in warm sodium carbonate solution, giving in each case deep orange-red solutions. When heated rapidly, it deflagrates and in a closed tube explodes violently. The hydrazine salt crystallises in orange needles, sparingly soluble in cold alcohol, but readily soluble in water. On heating, it deflagrates violently (Found: $\mathrm{N}=37 \cdot 4 . \quad \mathrm{C}_{7} \mathrm{H}_{6} \mathrm{O}_{3} \mathrm{~N}_{4}, \mathrm{~N}_{2} \mathrm{H}_{4}$ requires $\mathrm{N}=37 \cdot 2$ per cent.).

\section{2 : 4-Dinitro-m-tolylazoimide.}

To a hot, alcoholic solution of 2 grams of $2: 3: 4$-trinitrotoluene, 0.6 gram of sodium azide dissolved in alcohol was added. The solution assumed a red tint, and after boiling for a few minutes was diluted somewhat and cooled. The azoimide which separated was crystallised from alcohol, when it was obtained in silvery leaflets which turned pale green on exposure to light and melted at $89^{\circ}$; on stronger heating, it decomposed quietly and showed no tendency to explode (Found: $\mathrm{N}=31 \cdot 5 . \quad \mathrm{C}_{7} \mathrm{H}_{5} \mathrm{O}_{4} \mathrm{~N}_{5}$ requires $\mathrm{N}=313$ per cent.).

\section{2:4-Linitro-m-tolylhydrazones.}

The hydrazones were prepared by adding a slight excess of the aldehyde in alcoholic solution to a hot, alcoholic solution of the 
hydrazine, heating on the water-bath for some time, diluting somewhat with water, cooling, and crystallising the product from alcohol. In some cases, the hydrazone began to separate from the hot liquid, or crystallised on cooling without the addition of water, but the same process was adopted in each case for simplicity.

Formaldehyde-2:4-dinitro-m-tolylhydrazone crystallises in fine yellow needles melting at $132^{\circ}$ (Found: $\mathrm{N}=25 \cdot 0 . \quad \mathrm{C}_{8} \mathrm{H}_{8} \mathrm{O}_{4} \mathrm{~N}_{4}$ requires $\mathrm{N}=\mathbf{2 5 \cdot 0}$ per cent.).

Acetaldehyde-2 :4-dinitro-m-tolylhydrazone is a yellow, crystalline powder melting at $112^{\circ}$ (Found: $\mathrm{N}=\mathbf{2 4} \cdot 0 . \quad \mathrm{C}_{9} \mathrm{H}_{10} \mathrm{O}_{4} \mathrm{~N}_{4}$ requires $\mathrm{N}=23 \cdot 5$ per cent.).

n-Propaldehyde-2:4-dinitro-m-tolylhydrazone crystallises in long, orange-yellow tables melting at $100^{\circ}$ (Found : $\mathrm{N}=22 \cdot 2 . \quad \mathrm{C}_{10} \mathrm{H}_{12} \mathrm{O}_{4} \mathrm{~N}_{4}$ requires $\mathrm{N}=22 \cdot 2$ per cent.).

n-Butaldehyde-2:4-dinitro-m-tolylhydrazone forms orange-red prisms melting at $86^{\circ}$ (Found: $\mathrm{N}=\mathbf{2 1} \cdot 3 . \quad \mathrm{C}_{11} \mathrm{H}_{14} \mathrm{O}_{4} \mathrm{~N}_{4}$ requires $\mathrm{N}=21 \cdot 1$ per cent.).

Benzaldehyde-2:4-dinitro-m-tolylhydrazone forms orange-red needles melting at $188^{\circ}$ (Found: $\mathrm{N}=18 \cdot 8 . \quad \mathrm{C}_{14} \mathrm{H}_{12} \mathrm{O}_{4} \mathrm{~N}_{4}$ requires $\mathrm{N}=18 \cdot 7$ per cent.).

Acetone-2 : 4-dinitro-m-tolylhydrazone crystallises in long, orangered needles melting at $102^{\circ}$ (Found: $\mathrm{N}=22 \cdot 6$. $\mathrm{C}_{10} \mathrm{H}_{12} \mathrm{O}_{4} \mathrm{~N}_{4}$ requires $\mathrm{N}=22 \cdot 2$ per cent.).

Methyl ethyl ketone 2:4-dinitro-m-tolylhydrazone forms orangeyellow needles melting at $94^{\circ}$ (Found: $\mathrm{N}=21 \cdot 4 . \mathrm{C}_{11} \mathrm{H}_{14} \mathrm{O}_{4} \mathrm{~N}_{4}$ requires $\mathrm{N}=21 \cdot 1$ per cent.).

\section{3 : 5-Dinitro-o-tolylhydrazine.}

Two grams of $2: 3: 5$-trinitrotoluene were dissolved in 25 c.c. of boiling alcohol and 2 c.c. of hydrazine hydrate diluted with 10 c.c. of alcohol added. The mixture was at once cooled and the precipitated hydrazine crystallised from alcohol, in which it was sparingly soluble. $3: 5$-Dinitro-o-tolylhydrazine separates in orange, flaky needles melting and decomposing at $169^{\circ}$ (Found : $\mathrm{N}=\mathbf{2 6} \cdot 9$. $\mathrm{C}_{7} \mathrm{H}_{8} \mathrm{O}_{4} \mathrm{~N}_{4}$ requires $\mathrm{N}=\mathbf{2 6 . 4}$ per cent.). The compound was oriented by oxidation with cupric acetate (see above), the dinitrotoluene produced being the $3: 5$-isomeride.

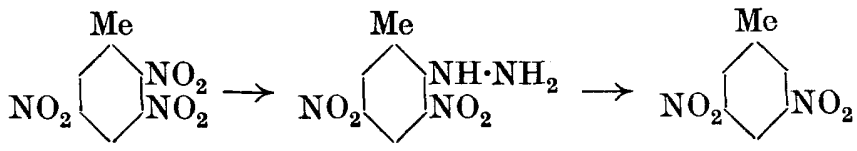

Acetone-3 : 5-dinitro-o-tolylhydrazone.-An alcoholic solution of the above hydrazine was boiled for a few minutes with a slight 
excess of acetone. On diluting with water and cooling, the hydrazone separated and was crystallised from alcohol, when it formed scarlet needles melting at $128^{\circ}$ (Found: $\mathrm{N}=22 \cdot 5 . \quad \mathrm{C}_{10} \mathrm{H}_{12} \mathrm{O}_{4} \mathrm{~N}_{4}$ requires $\mathrm{N}=\mathbf{2 2 \cdot 2}$ per cent.).

Benzaldehyde-3 : 5-dinitro-o-tolylhydrazone.-An alcoholic solution of the hydrazine was boiled with a slight excess of benzaldehyde. The derivative began to separate from the hot liquid, which was cooled, and the solid crystallised from a mixture of acetone and alcohol, when it separated as a crystalline, vermilion powder melting at $194^{\circ}$ (Found: $\mathrm{N}=18 \cdot 7 . \quad \mathrm{C}_{14} \mathrm{H}_{12} \mathrm{O}_{4} \mathrm{~N}_{4}$ requires $\mathrm{N}=18 \cdot 7$ per cent.).

\section{3 : 5-Dinitro-p-tolylhydrazine.}

This compound was prepared from $3: 4: 5$-trinitrotoluene in the same way as the dinitro-o-tolylhydrazine. In this case, however, there was a greater tendency to form the hydrazine salt of the benzotriazole, which, on account of its sparing solubility, was difficult to remove. Three crystallisations from alcohol, however, gave the pure hydrazine in lustrous, copper-coloured plates. These crystals, on grinding, gave a brown powder which turned bright red at $130^{\circ}$ and melted at $139^{\circ}$. The red substance, on cooling, did not change its colour, but crystallisation from alcohol produced the original copper-coloured compound (Found: $\mathrm{N}=\mathbf{2 6 \cdot 7}$. $\mathrm{C}_{7} \mathrm{H}_{8} \mathrm{O}_{4} \mathrm{~N}_{4}$ requires $\mathrm{N}=26.4$ per cent.). This compound was oriented as before by oxidation with cupric acetate to $3: 5$-dinitrotoluene.

Benzaldehyde-3 : 5-dinitro-p-tolylhydrazone, prepared in the same way as the dinitro-o-tolyl derivative, crystallises from acetone in scarlet leaflets melting at $214^{\circ}$ (Found: $\mathrm{N}=18 \cdot 8$. $\mathrm{C}_{14} \mathrm{H}_{12} \mathrm{O}_{4} \mathrm{~N}_{4}$ requires $\mathrm{N}=18.7$ per cent.).

\section{4-Nitro-1-hydroxy-6-methyl-1 : 2 : 3-benzotriazole.}

The above hydrazine in alcohol was boiled with hydrazine hydrate for some minutes. The hydrazine salt, which crystallised on cooling, was dissolved in hot water, the solution acidified with dilute hydrochloric acid, and cooled. The benzotriazole crystallised and was purified by crystallisation from dilute alcohol, when it separated in very pale yellow, silky needles which began to decompose above $200^{\circ}$ but did not melt at $230^{\circ}$ (Found: $\mathrm{N}=28.9$. $\quad \mathrm{C}_{7} \mathrm{H}_{6} \mathrm{O}_{3} \mathrm{~N}_{4}$ requires $\mathrm{N}=28.9$ per cent.). The hydrazine salt is sparingly soluble in cold, but readily soluble in hot water.

The Ratph Forster laboratory of Organic Chemistry, University College, London. [Received, May 10th, 1921.] 